\title{
Association of Vitamin D Status with Morbidity in Children with Sickle Cell Disease in Tertiary Care Hospital
}

\author{
(D) Dipty Jain1', (1) Hemanth Kumar²
}

${ }^{1}$ Government Medical College and Hospital Nagpur, Clinic of Paediatrics, Maharashtra, India

2Kasturba Hospital Mumbai, Clinic of Paediatrics, Maharashtra, India

\begin{abstract}
Aim: Children with sickle cell disease (SCD) are at high risk of vitamin D deficiency (VDD). The prevalence of VDD in different countries is between $65-100 \%$ in these patients. The present study was undertaken to find the prevalence of VDD among sickle cell children and to assess the association of co-morbidities with VDD.

Materials and Methods: Total 89 children who were attending a sickle cell clinic/admitted to paediatric wards of a Tertiary Care Centre were enrolled in this study. After their history, clinical examination and anthropometry were investigated, samples were taken for serum 25-hydroxy vitamin D ng/mL and calcium level assessment. The outcome was morbidity in sickle cell children in terms of frequency of pain episodes, number of febrile episodes, number of blood transfusions and total number of admissions.

Results: Out of 89 cases, 58 (65.17\%) cases were deficient in vitamin D ( $<20 \mathrm{ng} / \mathrm{dL}), 22$ (24.72\%) cases had insufficiency (20-30 ng/dL) and 9 $(10.11 \%)$ cases had normal vitamin D levels (>30 ng/dL). The mean vitamin D level was $19.42 \mathrm{ng} / \mathrm{dL}$. Morbidity in SCD was more in VDD children compared to vitamin $D$ sufficient children with significance in the number of pain episodes and the total number of hospital admissions but not in the number of admissions for acute febrile illness or the total number of blood transfusions.

Conclusion: VDD was prevalent in $65.17 \%$ of children with SCD. Children between 4-12 years were more affected with a male predominance. As this study involved children with SCD alone, future studies need to be carried out involving children without SCD to establish a better possible link between vitamin-D and SCD morbidity.

Keywords: Sickle cell, vitamin D, deficiency, co-morbidities, anthropometry, prevalence
\end{abstract}

\section{Introduction}

Sickle cell disease (SCD) is the most common hemoglobinopathy worldwide. It is caused by a mutation resulting from an exchange of nitrogenous bases in the sixth codon of the beta-globulin haemoglobin gene, generating abnormal haemoglobin called haemoglobin S (HbS) (1). SCD has a high prevalence in India, especially in the central and western regions, and has a considerable health burden (2). As per an Indian Council of Medical Research survey, about $20 \%$ of children with SCD expired by the age of two and $30 \%$ of children with SCD among the tribal community die before they reach adulthood $(2,3)$.

Children with sickle cell anaemia (SCA) have a higher risk of developing nutritional deficiencies due to reduced 
appetite (4), poor dietary intake of nutrients and infectious complications, (5) which demand greater attention from health care professionals. Among the vitamins, vitamin $D$ must be carefully evaluated in children with SCA because these patients are more likely to develop vitamin D deficiency (VDD) when compared to healthy controls (6). This is due to the high concentration of melanin in the skin, low levels of physical activity and low food intake (5). Calcium and vitamin $\mathrm{D}$ are important for bone metabolism, and low calcium intake leads to a reduction in the ideal bone mass peak in children and adolescents with SCA, which leads to growth failure (7). VDD, in turn, is associated with increased respiratory infections, muscle weakness and increased risk of falls and micro lesions (8).

In addition, SCD is a genetic disorder with various life-threatening organ-system complications like periodic vaso-occlusive crises, chronic haemolysis, jaundice, infarcts and acute chest syndrome (1). Vaso-occlusive crises are the result of interactions between sickle erythrocytes, inflammatory cytokines and endothelium. VDD, which has effects on endothelial dysfunction and cytokines, has possibly contributed to the pathogenesis of SCD (6). Patients exhibit elevated leukocyte counts, abnormal activation of granulocytes, monocytes, and endothelial cells, and increased levels of multiple inflammatory mediators. Finally, SCD is an inflammatory condition and vitamin D binding protein has been shown to decline in inflammatory conditions. New literature suggests there is an association between VDD and increased anaemia in patients with chronic anaemia (9). Patients with SCD are susceptible to all of these complications, although it is unclear to what extent VDD is a contributing causal factor.

VDD is seen frequently in patients with SCD and it has emerged as a public health focus in recent years for its contribution to adverse skeletal and extra-skeletal manifestations (10). However, the relationship between inflammation and VDD in SCD pathogenesis has not been investigated to date. VDD is common in Indian children and there is well documented literature showing vitamin $D$ in SCD is lower than in the general population (6). VDD can be reliably and inexpensively treated making it a prime intervention to potentially improve health outcomes among those with SCD. To date, prophylactic vitamin D supplementation is not practiced by a majority of physicians. Despite this evidence, VDD remains both under-recognized and under-treated in patients with SCD. Studies from other countries have documented that SCD children are 5.3 times more likely to be deficient in vitamin D compared to healthy controls (6). However, limited data is available from India with respect to the potential association between VDD and its association with the co-morbidities observed in SCA. Hence, the present study was conducted to study the association of vitamin $D$ status with morbidity in children with SCD.

\section{Materials and Methods}

The present cross-sectional study was conducted on 89 children of both sexes, aged between 2-18 years with SCD with "SS" and "SF" pattern, diagnosed by high-performance liquid chromatography, who were attending a sickle cell clinic or admitted to the paediatric wards of a Tertiary Care Centre in central India during a period of 2 years from September 2016 to August 2018. Children on hydroxyurea therapy, sickle cell children with chronic diseases or on vitamin $D$ supplementation were excluded from this study. Ethical clearance and approval was obtained from Institutional Ethical committee and written informed consent was taken from the parents of the patients.

A detailed history, clinical examination and anthropometry were taken and data was collected in structured data collection forms. Blood samples were drawn in plain tubes for 25-hydroxyvitamin $D$ [25(OH)D] and serum calcium. The estimation of vitamin $D$ was done by radio-immune assays using chemiluminescent protein binding assay because of unavailability and cost factors. The classification of VDD based on serum levels of vitamin D according to Indian paediatrics guidelines (11) are as follows; 1) deficiency $<20 \mathrm{ng} / \mathrm{dL}, 2$ ) insufficiency $20-30 \mathrm{ng} / \mathrm{dL}$ and 3 ) Sufficiency $>30 \mathrm{ng} / \mathrm{dL}$. Calcium was estimated by CALC Arsenazo III method. The outcome for morbidity in sickle cell children was determined in terms of the frequency of pain episodes, the number of admissions for acute febrile illness, the number of blood transfusions and the total number of admissions. Data for morbidity was obtained from the records in the sickle cell clinic and from a timeline which was given for sickle cell children.

\section{Statistical Analysis}

Statistical analysis was done by using the software, STATA, version 10.1; 2011. Descriptive statistics like mean, and standard deviation were used for quantitative measures while frequency and percentages were used to summarize qualitative measures. Inferential statistics included hypothesis testing procedures like Pearson's chi-square test for assessing differences in proportions and testing associations. Two-independent samples t-test was used for assessing differences in the means of groups. P-value less than 0.05 was considered statistically significant. 


\section{Observations and Results}

A total of 89 children with SCD (SS-88 children and SF-1 child) were enrolled in this study, of whom 50 (56\%) were males and 39 (44\%) were females. The majority of cases were in the age group of $>4-8$ years $(40.45 \%)$ followed by $>8-12$ years $(34.83 \%), 2-4$ years $(13.48 \%)$ and $>12-18$ years (11.24\%). The mean age of patients was $7.32 \pm 3.27$ years, ranging from 2.5-16 years.

VDD was reported in 58 (65.17\%) children with SCD, 22 (24.72\%) cases had insufficiency and 9 (10.11\%) cases had normal vitamin $D$ levels as depicted in Figure 1. The mean vitamin D level was $19.42 \mathrm{ng} / \mathrm{dL}$, ranging from 5.12 to 62.05 $\mathrm{ng} / \mathrm{dL}$.

Table I shows the comparison of vitamin D levels with age and sex, which also shows no relationship of vitamin $D$ levels with age and sex.

Nutrition status is classified into undernourished and normal based on WHO and CDC classification criteria. Out of 89 cases, 26 (29.21\%) children had normal nutrition and $63(70.79 \%)$ children were undernourished. VDD was more among undernourished than children with normal nutrition,

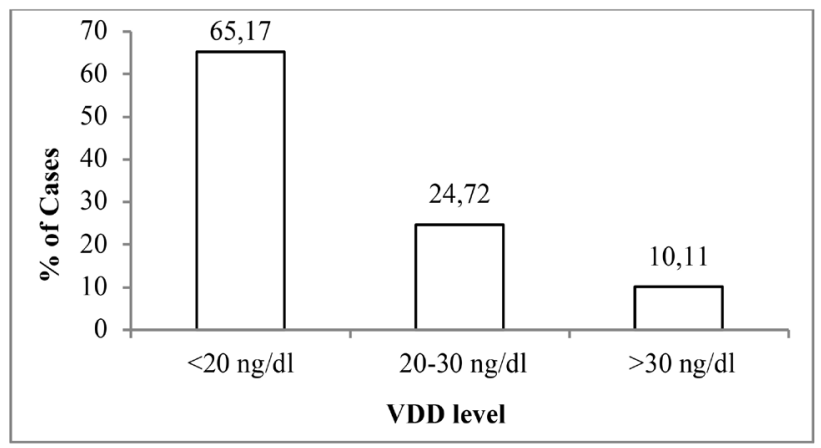

Figure 1. Distribution of cases according to vitamin D deficiency levels in SCD

SCD: Sickle cell disease, VDD: Vitamin D deficiency with a p-value of 0.001, which was statistically significant (Figure 2), (Table II).

1. Vitamin D deficiency in SCD children was associated with increased pain episodes compared to vitamin D sufficient children ( $p=0.001)$.

2. Number of hospital admissions for acute febrile illness had an inverse relationship with vitamin D levels with a p-value of 0.152 which was not statistically significant. Thus, VDD was associated with an increased risk for admissions for acute febrile illness but not significantly.

3. Number of blood transfusions had an inverse relationship with vitamin $D$ level with a $p$-value $=0.728$ which was not statistically significant.

4. Total number of hospital admissions had an inverse relationship with vitamin $D$ levels. Decrease in vitamin $D$ levels increases the number of total admissions in deficient group $>$ insufficient group $>$ normal vitamin $D$ level with a p-value $=0.018$.

The comparisons of mean values of co-morbidities (number of pain-crises, acute febrile illness, blood transfusions and total number of admission) between VDD and vitamin D sufficiency groups are shown in Table III. The mean number of pain episodes, admissions for acute febrile

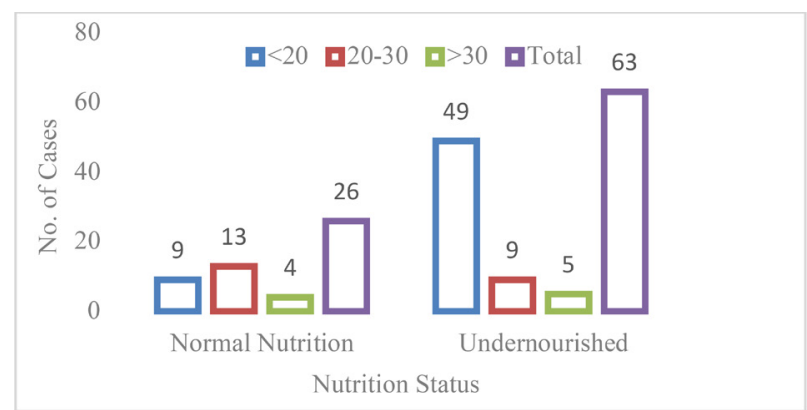

Figure 2. Association between vitamin $D$ levels and nutrition status

Table I. Comparison of vitamin D levels with age and sex

\begin{tabular}{|c|c|c|c|c|c|c|c|c|c|c|c|c|}
\hline \multirow{3}{*}{$\begin{array}{l}\text { Vitamin D level } \\
\text { in } \mathrm{ng} / \mathrm{dL}\end{array}$} & \multirow{3}{*}{$\begin{array}{l}\text { No. of cases } \\
(\%)\end{array}$} & \multicolumn{8}{|c|}{ Age group in years } & \multirow{2}{*}{\multicolumn{2}{|c|}{ Total }} & \multirow{3}{*}{ p-value } \\
\hline & & \multicolumn{2}{|c|}{$>2-4$} & \multicolumn{2}{|c|}{$>4-8$} & \multicolumn{2}{|c|}{$>8-12$} & \multicolumn{2}{|c|}{$>12-18$} & & & \\
\hline & & $M$ & $\mathbf{F}$ & M & $\mathbf{F}$ & $M$ & $\mathbf{F}$ & $M$ & $\mathbf{F}$ & $M$ & $\mathbf{F}$ & \\
\hline$<20$ & $58(65.17 \%)$ & 3 & 2 & 13 & 12 & 12 & 10 & 5 & 1 & $33(66 \%)$ & $25(64.1 \%)$ & \multirow{5}{*}{$\begin{array}{l}\text { Chi-square }(2)=2.42 \\
p=0.29\end{array}$} \\
\hline $20-30$ & $22(24.72 \%)$ & 2 & 2 & 6 & 3 & 5 & 2 & 1 & 1 & $14(28 \%)$ & $8(20.51 \%)$ & \\
\hline$>30$ & $9(10.11 \%)$ & 1 & 2 & 1 & 1 & 1 & 1 & 0 & 2 & $3(6 \%)$ & $6(15.38 \%)$ & \\
\hline Total & $89(100 \%)$ & 6 & 6 & 20 & 16 & 18 & 13 & 6 & 4 & $50(56.17 \%)$ & $39(43.82 \%)$ & \\
\hline $\mathrm{p}$-value & \multicolumn{11}{|c|}{ Chi-square $(6)=3.92, p$-value $=0.688$} & \\
\hline
\end{tabular}




\begin{tabular}{|c|c|c|c|c|c|}
\hline \multirow{2}{*}{ Vitamin D level in ng/dL } & \multicolumn{4}{|c|}{ Pain episodes category } & \multirow{2}{*}{ p-value } \\
\hline & $0-3$ & $>3-6$ & $>6-9$ & $>9$ & \\
\hline$<20$ & $9(27.27 \%)$ & $34(82.93 \%)$ & $13(92.86 \%)$ & $2(66.67 \%)$ & \multirow{3}{*}{0.001} \\
\hline $20-30$ & $16(48.48 \%)$ & $6(14.63 \%)$ & $1(7.14 \%)$ & $1(33.33 \%)$ & \\
\hline$>30$ & $8(24.24 \%)$ & $1(2.44 \%)$ & $0(0.0 \%)$ & $0(0.0 \%)$ & \\
\hline \multirow{2}{*}{ Vitamin D level in ng/dL } & \multicolumn{4}{|c|}{ Hospital admissions for acute febrile illness } & \multirow{5}{*}{0.152} \\
\hline & $0-2$ & $>2-4$ & $>4-6$ & $>6$ & \\
\hline$<20$ & $19(51.35 \%)$ & $29(78.38 \%)$ & $5(62.5 \%)$ & $5(71.43 \%)$ & \\
\hline $20-30$ & $14(37.84 \%)$ & $4(10.81 \%)$ & $3(37.5 \%)$ & $1(14.29 \%)$ & \\
\hline$>30$ & $4(10.81 \%)$ & $4(10.81 \%)$ & $0(0 \%)$ & $1(14.29 \%)$ & \\
\hline \multirow{2}{*}{ Vitamin D level in ng/dL } & \multicolumn{4}{|c|}{ Number of blood transfusions } & \multirow{5}{*}{0.728} \\
\hline & $0-4$ & $>4-8$ & $>8-12$ & $>12$ & \\
\hline$<20$ & $51(65.38 \%)$ & $6(66.67 \%)$ & $0(0.00 \%)$ & $1(100 \%)$ & \\
\hline $20-30$ & $19(24.36 \%)$ & $2(22.22 \%)$ & $1(100 \%)$ & $0(0.00 \%)$ & \\
\hline$>30$ & $8(10.26 \%)$ & $1(11.11 \%)$ & $0(0.00 \%)$ & $0(0.00 \%)$ & \\
\hline \multirow{2}{*}{ Vitamin D level in ng/dL } & \multicolumn{4}{|c|}{ Hospital admissions category } & \multirow{5}{*}{0.018} \\
\hline & $0-5$ & $>5-10$ & $>10-15$ & $>15$ & \\
\hline$<20$ & $11(37.93 \%)$ & $34(80.95 \%)$ & $9(69.23 \%)$ & $4(80 \%)$ & \\
\hline $20-30$ & $12(41.38 \%)$ & $6(14.29 \%)$ & $3(23.08 \%)$ & $1(20 \%)$ & \\
\hline$>30$ & $6(20.69 \%)$ & $2(4.76 \%)$ & $1(7.69 \%)$ & $0(0.00 \%)$ & \\
\hline
\end{tabular}

Table III. Comparison of mean values of co-morbidities between vitamin D deficiency and vitamin D sufficiency group

\begin{tabular}{|l|l|l|l|}
\hline Co-morbidities & VDD group & Vitamin D sufficiency group & p-value \\
\hline Number of pain episodes & $5.60 \pm 3.25$ & $2.22 \pm 1.64$ & 0.01 \\
\hline Number of admissions for acute febrile illness & $3.48 \pm 1.76$ & $2.66 \pm 1.93$ & 0.09 \\
\hline Number of blood transfusions & $3.00 \pm 5.25$ & $1.55 \pm 1.81$ & 0.4 \\
\hline Total number of hospital admissions & $9.01 \pm 5.30$ & $5.11 \pm 3.01$ & 0.02 \\
\hline VDD: Vitamin D deficiency & & \\
\hline
\end{tabular}

illness, blood transfusion and total admissions was more in the VDD group than the vitamin D sufficiency group.

\section{Discussion}

In the present study, the most common age group of SCD patients was 4 to 8 years, similar to that reported in the Garrido et al. (12) study. A male predominance was observed, which may be due to the fact that, in India, there is a lower healthcare utilization rate among females (13). Children with SCD are more prone to nutritional deficiency. VDD is one of the most common nutrient deficiencies among children with SCD. The prevalence of VDD in young children is around $50-90 \%$ in the Indian subcontinent (14). In the current study, VDD was found in 58 (65.17\%) children, insufficiency in $22(24.72 \%)$ and sufficient in 9 $(10.11 \%)$ children with SCD. Thus, the study shows that $90 \%$ of children were below $30 \mathrm{ng} / \mathrm{dL}$ and $65.17 \%$ of children were deficient. These results correlated well with previous studies $(12,15,16)$. Rovner et al. (6) defined VDD as a vitamin $D$ level less than $11 \mathrm{ng} / \mathrm{mL}$ and insufficiency as a vitamin D level between 11 to $<30 \mathrm{ng} / \mathrm{mL}$. They found that $33 \%$ of children with HbSS were deficient, compared with only $9 \%$ of healthy children. The current study found that only $20 \%$ of children had VDD $<11 \mathrm{ng} / \mathrm{dL}$, so VDD is highly prevalent 
in children with SCD. The mean vitamin D level was 19.42 $\mathrm{ng} / \mathrm{dL}$, which is comparable with the study done by Winters et al. (17) where they found the mean [25(OH)D] level was $17.2 \pm 9.5 \mathrm{ng} / \mathrm{dL}$.

There was no correlation between vitamin D level and sex. There was an inverse relationship between age and vitamin $D$ level but it was not statistically significant $(p=0.688)$. Similar results are reported in the study conducted by Adewoye et al. (18) and Allama et al. (19). VDD was more in undernourished children than in children with normal nutrition. Jackson et al. (20) reported vitamin $D$ levels were not significantly correlated with body mass index (BMI) percentile $(p=1.00) / B M I Z$-score $(p=0.53)$. Ozen et al. (21) found vitamin $D$ levels were significantly lower in children whose height and/or weight were $>2$ standard deviation below the mean.

There was low vitamin D level found in an existing study which was associated with an increase in the frequency of painful crises. Vaso-occlusive crises are the result of interactions between sickle erythrocytes, inflammatory cytokines and endothelium. VDD, which has effects on endothelial dysfunction and cytokines, has possibly contributed to the pathogenesis of SCD (7). Serum $[25(\mathrm{OH})$ D] $\mathrm{ng} / \mathrm{mL}$ is a negative acute phase reactant, which has implications for acute and chronic inflammatory diseases. Serum [25(OH)D] $\mathrm{ng} / \mathrm{mL}$ is an unreliable biomarker of vitamin D status after acute inflammatory insult (22). This may be the reason behind the increased severity of bone pain and hospitalisation due to vaso-occlusive crises. Lee et al. (16) found similar findings that serum $[25(\mathrm{OH})$ D] $\mathrm{ng} / \mathrm{mL}$ was associated with pain, but no significant association between serum [25(OH)D] ng/mL and acute chest syndrome. Osunkwo et al. (23) also found a significant association between VDD and painful crises. Shams et al. (24) found vitamin $D$ administration was associated with lower postoperative analgesia requirement and postoperative complication. There was an increased risk of admissions in vitamin D deficient sickle cell children compared to vitamin $D$ sufficient children but this was not statistically significant $(p=0.220)$. In children with low levels of vitamin $D$, there was an increase in the number of blood transfusion but this was not statistically significant $(p=0.728)$. These findings are in accordance with earlier studies $(25,26)$. Total number of hospitalizations was inversely proportional to the vitamin D level $(p=0.018)$. McCaskill et al. (27) also found similar results that vitamin $D$ serum levels are inversely associated with medical record reported hospitalizations visits $(p=0.04)$.

\section{Study Limitations}

The seasonal variation of vitamin $D$ levels was not considered in the present study. The presence of sickle cell nephropathy, which could significantly contribute to development of VDD, was not evaluated. We also did not determine the prevalence of lactose intolerance, the dietary intake of vitamin D or other life style factors which could affect the development of VDD in this population. In order to understand the relationship between vitamin $D$ and co-morbidities, a molecular study needs to be carried out in patients with SCD to observe changes occurring in the presence of decreased levels of vitamin D.

\section{Conclusion}

Vitamin D was one the most common nutrient deficiencies encountered in sickle cell children with a prevalence of $65.17 \%$ in the present study. Therefore, the authors suggest regular monitoring of serum vitamin $D$ levels in patients with SCD and, subsequently, supplements to relieve pain, enhance efficiency, reduce the development of anaemia and reduce the requirement of hospital admission in patients with insufficient vitamin D. As this study involved children with SCD alone, a future study needs to be carried out involving children without SCD to establish a better possible link between vitamin D and SCD morbidity.

A clinical trial with vitamin $D$ supplementation is planned. This trial will help us to prove the hypothesis that there is indeed a relation between vitamin $\mathrm{D}$ and sickle cell anaemia.

\section{Ethics}

Ethics Committee Approval: The study was given the Institutional Ethical committee approval from Government Medical College, Nagpur Maharashtra, India (protocol no: 201627, date: 14.10.2016).

Informed Consent: Written informed consent was obtained from the parents.

\section{Authorship Contributions}

Concept: D.J., Design: D.J., H.K., Data Collection or Processing: D.J., H.K., Analysis or Interpretation: D.J., H.K., Literature Search: D.J., H.K., Writing: D.J., H.K.

Conflict of Interest: There is no conflict of interest is declared by the authors.

Financial Disclosure: The authors declare that this study received no financial support. 


\section{References}

1. Zago MA, Pinto AC. The pathophysiology of sickle cell disease: from the genetic mutation to ultiorgan disfunction. Rev Bras Hematol Hemoter 2007; 29:2007-14.

2. Tewari S, Rees D. Morbidity pattern of sickle cell disease in India: a single centre perspective. Ind J Med Res. 2013; 138:288-90.

3. Rupani MP, Vasava BC, Mallick KH, Gharat VV, Bansal R. Reaching community through school going children for sickle cell disease in Zankhvav village of Surat district, Western India. Online I Health Allied Sci 2012; 2:1-3

4. Mitchell MJ, Kawchak DA, Stark L), Zemel BS, Ohene-Frempong $\mathrm{K}$, Stallings VA. Brief report: parent perspectives of nutritional status and mealtime behaviors in children with sickle cell disease. J Pediatr Psychol 2004; 29:315-20.

5. Kawchak DA, Schall II, Zemel BS, Ohene-Frempong K, Stallings VA. Adequacy of dietary intake declines with age in children with sicklecell disease. I Am Diet Assoc 2007; 107:843-84.

6. Rovner AJ, Stallings VA, Kawchak DA, Schall II, Ohene-Frempong $\mathrm{K}$, Zemel BS. High risk of vitamin D deficiency in children with sickle cell disease. I Am Diet Assoc 2008; 108:1512-6.

7. Institute of Medicine. Standing Committee on the Scientic Evaluation of Dietary Reference Intakes. Dri dietary reference intakes for calcium, phosphorus, magnesium, vitamin D, and fluoride. Washington: National Academy Press; 1997. pp. 250-87.

8. Holick MF. The D-lightful vitamin D for child health. JPEN J Parenter Enteral Nutr 2012; 36(Suppl 1):9S-19.

9. Busse JA, Seelaboyina KN, Malonga G, Moulton T. A patient event diary improves self-management inpediatric sickle cell disease patients. Blood 2013; 122:1723.

10. Holick MF. Vitamin D deficiency. N Engl I Med 2007; 357: 266-81.

11. Holick MF, Binkley NC, Bischoff-Ferrari HA, et al. Evaluation, treatment, and prevention of Vitamin D deficiency: an endocrine society clinical practice guideline. I Clin Endocrinol Metab 2011; 96:1911-30.

12. Garrido C, Cela E, Belendez C, Mata C, Huerta J. Status of vitamin $D$ in children with sickle cell disease living in Madrid, Spain. Eur J Pediatr 2012; 171:1793-8.

13. Vlassoff C. Gender differences in determinants and consequences of health and illness. I Health Popul Nutr 2007; 25:47-61.

14. Ritu G, Gupta A. Vitamin D deficiency in India: prevalence, causalities and interventions. Nutrients 2014; 6:729-75.
15. Ozdemir ZT, Ozkan EA, Akkoca AO, et al. Osteoporosis and Vitamin D Deficiency in Patients with Sickle Cell Disease. I Clin Anal Med 2016; 7:483-7.

16. Lee MT, Licursi M, McMahon DJ. Vitamin D deficiency and acute vaso-occlusive complications in children with sickle cell disease. Pediatr Blood Cancer 2015; 62:643-7.

17. Winters AC, Kethman W, Kruse-Jarres R, Kanter J. Vitamin D insufficiency is a frequent finding in pediatric and adult patients with sickle cell disease and correlates with markers of cell turnover. I Nutr Disorders Ther 2014; 4:1000140.

18. Adewoye $\mathrm{AH}$, Chen $\mathrm{TC}, \mathrm{Ma} \mathrm{Q}$, et al. Sickle cell bone disease: response to vitamin D and calcium. Am J Hematol. 2008; 4:2714.

19. Allama A, AlKhalifah M, Al-Dabbous IA, Alqudaihi G. Vitamin D deficiency in sickle cell disease patients in the Eastern Province of Saudi Arabia. Ann Saudi Med 2018; 38:130-6.

20. Jackson TC, Krauss MJ, Debaun MR, Strunk RC, Arbeláez AM. Vitamin D deficiency and comorbidities in children with sickle cell anemia. Pediatr Hematol Oncol 2012; 29:261-6.

21. Ozen S, Unal S, Ercetin N, Tasdelen B. Frequency and risk factors of endocrine complications in Turkish children and adolescents with sickle cell anemia. Turk J Haematol 2013; 30:25-31.

22. Graham R. Searjeant. Distribution of sickle cell disease. In: Graham R. Searjeant Sickle cell disease, third edition. Pg-23. Oxford university press, 2001.

23. Osunkwo I, Hodgman El, Cherry K, et al. Vitamin D deficiency and chronic pain in sickle cell disease. Br I Haematol 2011; 153:538-40

24. Shams T, Al Wadani H, El-Masry R, Zakaria O. Effect of prophylactic vitamin $D$ on anesthetic outcome in children with sickle cell disease. I Anaesthesiol Clin Pharmacol 2014; 30:20-4.

25. Grégoire-Pelchat $P$, Alos N, Ribault V, Pastore $Y$, Robitaille N, Mailhot G. Vitamin D Intake and Status of Children With Sickle Cell Disease in Montreal, Canada. J Pediatr Hematol Oncol 2018; 40:e531-6.

26. Jennifer AB, Seelaboyina KN, Malonga G, Setty MJ, Moulton T. Vitamin $D$ level and its correlation with hemoglobin in pediatric sickle cell disease patients. Blood 2013; 122:4677.

27. McCaskill ML, Ogunsakin O, Hottor T, Harville EW, Kruse-Jarres R. Serum 25-hydroxyvitamin $d$ and diet mediates vaso-occlusive related hospitalizations in sickle-cell disease patients. Nutrients 2018; 10:1384 